\title{
Production and uncertain green subcontracting control for an unreliable manufacturing system facing emissions
}

\author{
A. Ben-Salem ${ }^{\mathrm{a}}$, A. Gharbi ${ }^{\mathrm{a}^{*}}$, A. Hajji ${ }^{\mathrm{b}}$ \\ a Automated Production Engineering Department, École de technologie supérieure, \\ Production System Design and Control Laboratory, University of Quebec, 1100 Notre- \\ Dame Street West, Montreal, QC, Canada H3C $1 \mathrm{~K} 3$ \\ b Department of Operations and Decision Systems \& CIRRELT, Laval University. \\ Pavillon Palasis-Prince 2325, rue de la Terrasse Québec (Québec) G1V0A6
}

\begin{abstract}
Faced with environmental legislation imposed by authorities, manufacturers must review their short- and mid-long term strategies in order to integrate the environmental dimension into the decision making process. In that context, in this paper, we address the problem of an unreliable manufacturing system producing one product family type to meet a demand. We consider that the manufacturing system's operations generate harmful emissions into the environment. Hence, in addition to inventory, production and backlog costs, an environmental penalty is imposed when the emission level reaches a specific limit (cap approach). Because technology investments in production clean processes is often heavy and to improve its environmental strategy, we consider that demand can be partially satisfied by an unreliable subcontractor. The subcontractor which is characterized by a high development and innovation on sustainable technology requires a high selling cost and a random availability. This work examines this decision making problem in order to propose a new joint production and subcontracting control policy which takes into account the emission level. The objective is to optimize the total cost, which includes the inventory, backlog, production, emission and subcontracting costs, over an infinite horizon. An experimental approach combining simulation, experimental design and response surface methodology is used to solve the problem. Through numerical examples and further sensitivity analysis, the structure of the control policy is confirmed and analyzed. Thanks to the practical usefulness of the resolution approach, we provide a decision support system to help managers in deciding whether or not to subcontract, depending on green subcontractor characteristics (availability and cost).
\end{abstract}

Keywords: Unreliable manufacturing system, uncertain green subcontractor, production, emission, experimental resolution approach, decision support. 


\section{Introduction}

The paper aims to develop a coordination strategy between a less green company that generates harmful emissions and another company with a high and innovative green technology in order to reduce environmental damage which is never considered in the past works. Then, inspired by industrial practices, we investigate the possibility of taking advantage of developed green subcontracting as an external source (outsourcing) for the company in order to reduce costs (storage, production and environmental cost) and improve the environmental management strategy. In a dynamic and stochastic context (failure, repair activities, availability), a new structure of feedback production control policy is proposed in order to take into account the environmental aspect in the production as well as the subcontracting decisions.

The literature presents several approaches that have been developed to provide better control and management of unreliable manufacturing systems. Feedback control policies are among the topics that have attracted the attention of many researchers. Through several research studies, such policies have been proven to be efficient in managing random events in a stochastic and dynamic manufacturing environment. In that context, the hedging point policy (HPP) was developed for a manufacturing system composed of a single machine subject to failures and repairs (Kenné and Gharbi, 2000). This policy considers the production rate as a control variable, while the state of the system and the inventory level are state variables. This involves maintaining the stock level at a specific threshold when the production system is available, in order to avoid backlogs during failure periods. The concept of HPP has evolved to include the study of more complex problems based essentially on HPP extensions to specific areas, such as preventive maintenance (Kouedeu et al., 2014), supply chain (Hajji et al., 2009), setup (Assid et al., 2014), quality (Rivera-Gomez et al., 2013) and subcontracting (Hajej et al., 2014)).

Recently, the integration of environmental aspects into manufacturing systems control has begun to attract the attention of researchers. In the context of the optimal control theory, Ben-Salem et al. (2015b) studied a pollutant manufacturing system composed of a single machine subject to random failures and repair activities, and producing a single type of product. Under the emission cap approach, the authors developed a control policy 
with multiple thresholds, called EHPP, which integrates the emission level into the production decision. The results showed that EHPP has an economic advantage and reduces the emission balance compared to the classical HPP. The same authors in BenSalem et al. (2015a) developed a relationship between the equipment degradation phenomena and the emissions generated by a production facility which is never considered in the past works. Moreover, various aspects that can influence the process of decision making are considered simultaneously. Results showed that the multi-hedging point policy, which takes into account the emission level, has given an economic gain and reduced the environmental damage (emission generated). Li (2014) focused on the problem of production and maintenance control for a manufacturing system subject to quality deterioration under the emission tax approach. In addition to production and maintenance rates, the author considers the rate of investment in pollution R\&D as a decision variable. Drake et al. (2012) investigated the importance of technology choice and capacity decision in the context of emission control. Among the important results obtained by the authors was the finding that the choice of technology could reduce emissions. However, as mentioned by Baas (2007) and Cebon (1993), the integrating of green and ecologic aspect in the manufacturing domain can face financial obstacles, lack of expertise, difficulty in implementation and various other constraints. Until today, many companies have not yet invested enough in sustainable technologies despite governments' encouragement. Then, manufacturing companies that work with less green technologies can found an opportunity to use outsourcing with high green and innovative technology (Ramudhin et al. (2008), Brown (2008)). As a consequence, in one part, environmental damage will be limited by reducing the emission. In the other part, subcontracted products can also be beneficial if we consider environmental cost that the company would have to pay (Lambert et al., 1996). This partnership could be used in various industrial domains such as mining industries (Sivakumer et al. 2014). In the same context, Kumar and Subrahmanya (2010) indicate that big companies develop a subcontracting relationship with small and medium enterprises (SMEs) in automobile industry. The authors said that big companies take advantage from high and innovative subcontractor technology in order to enhance the economic performance. 
Regarding subcontracting, we should note that several research studies have shown that outsourcing can help the company achieve its objectives, such as reducing inventory and backlog costs (Abernathy et al., 2000). In the literature, the problem of in-house production and outsourcing has been the subject of several research papers. Among them, Dahane et al. (2011) addressed the joint production maintenance control problem in a subcontracting environment. In addition to the production system composed of a machine M1, the authors consider an unreliable subcontracting machine M2 characterized by a constant failure rate. Machine M2 is used because of the capacity lack of the machine M1 in order to meet a constant demand. Analytical and simulation models are developed to study the performance of the production system when governed with an integrated maintenance-subcontracting strategy. Bradly (2004) considered the production/inventory problem for a manufacturing system that can take advantage of two subcontractors to meet a stationary demand. Based on the approximations of Brownian, the author developed a model that approximates the optimal threshold of the basic stock for an M/M/1 system. The results obtained showed that for this system, the threshold policy (HPP) is optimal when the second subcontractor is used in preventive mode to build up the stock (make-to-stock) or to solve the problem of expected orders (make-to-order). Bradly considered that the subcontractor is always available. Yang et al. (2005) studied an inventory/production system with Markovian capacity and the possibility of subcontracting when production cannot meet demand. The authors considered a reliable subcontractor, but this assumption may not be very realistic in practice. In the context of subcontractor unavailability, Tan (2004) presented and studied a model composed of a manufacturer and an unreliable subcontractor with random demand. The author considered that the subcontractor provides services to several manufacturers, and as a result, may not be available to satisfy demand immediately. The problem was modeled analytically based on the stochastic control theory (continuous flow, discrete state) and a multiple HPP was proposed. The author showed that the immediate unavailability of the subcontractor allows him to benefit from demand pooling and reduce his optimal capacity and propose a lower cost. As in Tan (2004), the unreliable subcontractor is considered in this paper. However, we will investigate the problem at the producer level, which is different from Tan, who focused on the behaviour of the subcontractor in the face of 
demand fluctuations. In our study, we consider that the uncertainty of the subcontractor availability is due to his production facility maintenance. Indeed, maintenance activities aim to keep his production system at a high green level and limit the environmental damages as in Ben-Salem et al. (2015a). After random production stoppages, maintenance activities are conducted and subcontractor can again provide products to partners.

In the light of the enhanced requirements mentioned and the new reality faced, the main contribution of this paper is to provide decision makers with manufacturing strategies that incorporate both economic and environmental dimensions. Compared to other works in this domain, first, the paper focus on the problem under stochastic dynamic context. Moreover, various aspects that can influence the process of decision making are considered simultaneously (production, inventory, emission, subcontracting) which is never considered in the literature. The study considers also the integration of the concept of green and innovative outsourcing to limit the environmental damage (emission generated) and enhance economic performance which is an important point of difference with other works.

We thus address the problem of an unreliable manufacturing system that generates emissions in the context of environmental legislation. The manufacturing company, which does not yet migrated to green production technologies, is facing environmental constraints and wants to improve its green aspect by reducing emissions and optimize costs. As a solution, we assume that the company can develop a partnership with subcontracting innovative green companies in order to limit its harmful emissions and improve economic performance.

In this work, we combine the environmental aspects in a manufacturing system control with the concept of outsourcing. Therefore, a joint production, emission and subcontracting feedback control policy is developed. The objective is to measure the effectiveness of using green outsourcing to improve the company's environmental strategy and minimize the total cost. In this paper, we propose an experimental resolution approach combining simulation, experimental design and response surface methodology. 
The rest of the paper is organized as follows: The notations used herein, as well as a description of the studied system are presented in Section 2. The proposed control policy is described in detail in Section 3. In Sections 4 and 5, the resolution approach and the simulation model are presented, respectively. A numerical example and the sensitivity analysis are developed in Section 6. Section 7 presents a decision support tool for choosing whether or not to use a subcontractor based on characteristics (cost and availability). Finally, Section 8 concludes the paper and summarizes the results.

\section{Problem statement}

\subsection{Notation}

The following notations are used in this paper:

$\begin{array}{cl}\boldsymbol{x}(\boldsymbol{t}) & \text { Inventory level } \\ \boldsymbol{x}_{\boldsymbol{\theta}} & \text { Initial inventory level } \\ \boldsymbol{u}_{\boldsymbol{I}}(\boldsymbol{t}) & \text { Production rate } \\ \boldsymbol{u}_{\boldsymbol{2}}(\boldsymbol{t}) & \text { Subcontracting rate } \\ \boldsymbol{e}(\boldsymbol{t}) & \text { Emission level } \\ \boldsymbol{U}_{\boldsymbol{m a x}} & \text { Maximum production rate of the manufacturing system } \\ \boldsymbol{d} & \text { Demand rate } \\ \boldsymbol{L}_{\boldsymbol{s}} & \text { Standard permitted limit of emission } \\ \boldsymbol{L}_{\boldsymbol{v}} & \text { Voluntary limit of emission } \\ \boldsymbol{\theta} & \text { Emission index } \\ \boldsymbol{T}_{\boldsymbol{i}} & \text { Length of emission control period } \\ \boldsymbol{N} & \text { Number of periods in the planning horizon } \\ \boldsymbol{\rho} & \text { Discount rate } \\ \boldsymbol{D} \boldsymbol{s} & \text { Subcontractor availability } \\ \boldsymbol{D} \boldsymbol{p} & \text { Production system availability } \\ \boldsymbol{C}^{+} & \text {Holding cost/Unit/Time unit } \\ \boldsymbol{C}^{-} & \text {Backlog cost/Unit/Time unit } \\ \boldsymbol{C}^{\boldsymbol{e}} & \text { Penalty cost for emissions/Unit } \\ \boldsymbol{C}_{\boldsymbol{p}} & \text { Production cost/Unit } \\ \boldsymbol{C}_{\boldsymbol{s}} & \text { Subcontracting cost/Unit } \\ \boldsymbol{Z} & \text { Hedging level } \\ \boldsymbol{M T T F} & \text { Mean Time To Failure of the production system } \\ \boldsymbol{M T T R} & \text { Mean Time To Repair of the production system } \\ \boldsymbol{M T S G} & \text { Mean Time to Stop the production system of the Green subcontractor } \\ \boldsymbol{M T M G} & \text { Mean Time to Maintenance of the production of the Green subcontractor } \\ & \end{array}$

\subsection{Problem description}


We study a manufacturing system composed of a production facility subject to random failures and repair activities, and producing one product family type to meet a constant demand rate. Because of the harmful emissions into the environment caused by the operations of the manufacturing facility, production may incur sanctions imposed by the relevant authorities. To counter its increase in-house total cost (inventory, backlog, production and emission costs) and to improve its environmental management strategy, the company can meet demand through subcontractor characterized by clean and innovative production technology. Figure 1 presents the system under study.

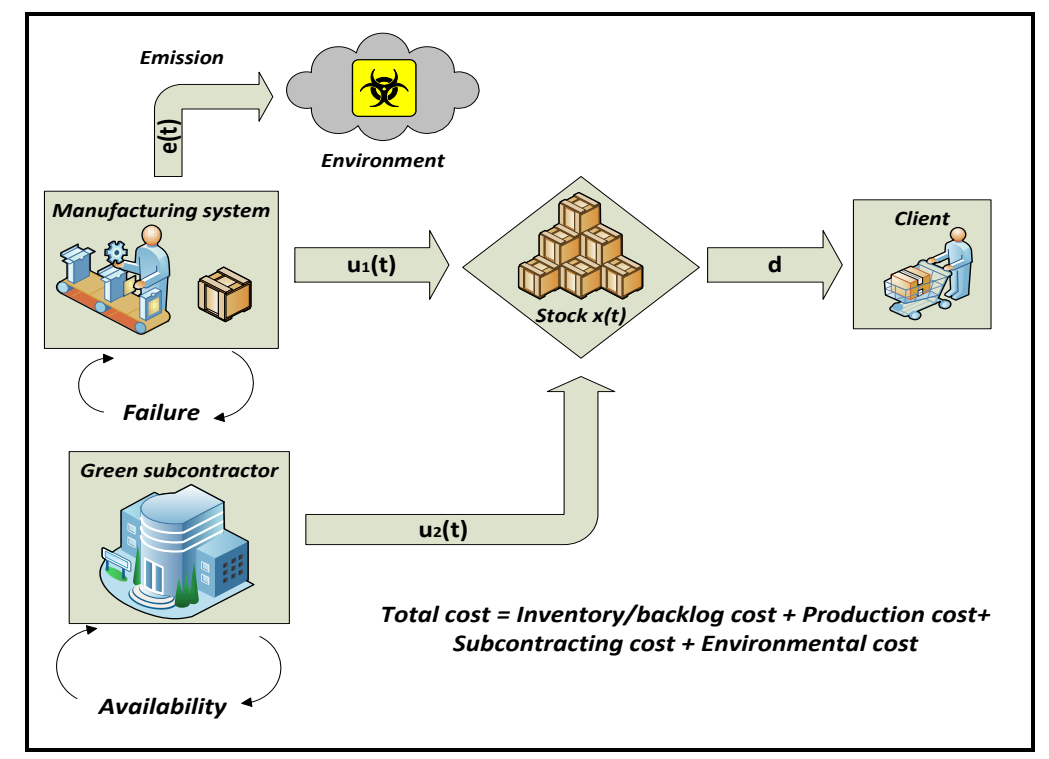

Figure 1: system under study

As shown in Figure 1, the manufacturing system makes products at a rate $u_{1}(t)$ to build a stock $x(t)$. In addition to the inventory, backlog and production costs, emission generated at a rate $\dot{e}(t)$ can generate an environmental cost under the emission cap approach. This cost is due to the emission penalty paid by the company when its emission level in a control period (e.g., one year) exceeds a standard limit ( $L s)$ fixed by the authorities (Chen et al., 2013). Faced with the increase in in-house costs, a green subcontracting, at a rate $u_{2}(t)$, is one of the effective solutions that can help meet customer demand, keep its customers confidence and reduce the emissions. Because of his production system maintenance activities, we assume that the subcontractor will not always provide additional capacity to the company. 
Given the significant compromise that must take place between in-house production and emissions, the main objective of this paper is to propose a feedback adaptive policy which provides a better control of the production and the subcontracting rate, taking into account the environmental aspect.

For any specific time t, the manufacturing system and the subcontracting states can be described by a continuous-time discrete-space stochastic process $\{\alpha(t), t>0\} \in \mathrm{I}\{0,1\}$ and $\{\beta(t), t>0\} \in \mathrm{I}\{0,1\}$, respectively, with $\alpha(t)=1$ when the system is operational, $\alpha(t)=0$ if the system is under repair, $\beta(t)=1$ when the subcontractor is available, and $\beta(t)=0$ if the subcontractor is unavailable. Note that in Tan (2004), the subcontractor can be unavailable only at the beginning of the subcontracting process. However, in our study, we assume that the subcontractor unavailability is due to his manufacturing system random stoppage and maintenance activities. Let $D_{s}$ be equaled to $\frac{M T S G}{M T S G+M T M G}$, it is the fraction of time in which the subcontractor is available. In the same context, we define $D_{p}$ as the production system availability which is equal to $\frac{M T T F}{M T T F+M T T R}$. Hence, the state of the production system and subcontractor can be described by the state variables $(x(t), \alpha(t), \beta(t))$, with $x(t) \in \mathrm{R}, \alpha(t)$ and $\beta(t) \in \mathrm{I}=\{0,1\}$.

The differential equation (1) presents the inventory dynamic:

$$
\frac{d x(t)}{d t}=u_{1}(t)+u_{2}(t)-d, x(0)=x O
$$

The production rate, at any time $t$, must satisfy the capacity constraint of the production system given by equation (2):

$$
0 \leq u_{1}(t) \leq U_{\max }
$$

Given the random unavailability of the production system, its capacity must satisfy, at the very least, the demand rate presented as follows:

$$
\mathrm{d} \leq U_{\max } \times D_{p}
$$


Inequality (3) shows that all the demand can be satiated from in-house production. However, in this work, subcontracting is used to reduce emissions and the environmental penalty.

When processing at a rate $u_{1}(t)$, the system generates a quantity of harmful pollutants $\theta$, called the emission index, for each part produced. The dynamic behaviour of the quantity of emissions is given by equation (4):

$$
\frac{d e(t)}{d t}=u_{1}(t) \times \theta
$$

To take account of the stochastic aspect of emissions, we adopt $\theta$ as a random variable that follows a uniform distribution [a, b] as in Chen and Monahan (2010).

\subsection{Cost function}

The instantaneous inventory, backlog, production and subcontracting cost function $g_{1}($. is given by the following equation:

$$
g_{1}\left(x(t), u_{1}(\mathrm{t}), u_{2}(\mathrm{t})\right)=C^{+} x^{+}+C^{-} x^{-}+C_{\mathrm{p}} u_{1}(\mathrm{t})+C_{\mathrm{s}} u_{2}(\mathrm{t})
$$

where $x^{+}=\max (0, x), x^{-}=\max (-x, 0)$.

The emission cost at the end of reference periods $i$ is given by the following equation:

$$
g_{2}\left(t_{i}\right)=C^{e} \times \max \left(0, e\left(t_{i}\right)-L s\right), i=0, . ., N
$$

Hence, the total cost $J($.$) can be defined by the equation (7) using g_{1}($.$) and g_{2}($.$) :$

$$
J(x, e, \alpha, \beta)=\int_{0}^{\infty} e^{-\rho t} g_{1}\left(x(t), u_{1}(\mathrm{t}), u_{2}(\mathrm{t})\right) d t+\sum_{i=1}^{\infty} e^{-\rho t_{i}} g_{2}\left(t_{i}\right)
$$

The production and subcontracting planning problem considered here is to find an admissible decision or control policy that minimizes $J($.$) , given by (7), subject to$ equations (1) to (4). Hence, the objective is to determine the production and the subcontracting rates as a function of the inventory level, the emission level, the production system and the subcontractor states, in order to minimize the total cost. 


\section{Control policy}

An extended version of HPP taking into account the subcontracting possibility and environmental aspects is developed in this section. As presented in the introduction, for continuous flow manufacturing systems, HPP is optimal for the same class of system (Kenné and Gharbi, 2000), but without considering emission or subcontracting. From an operational standpoint, to control the manufacturing system under study, the manager must choose between reducing production and accepting backlog costs or increasing production and accepting inventory and emission costs. In an unreliable manufacturing environment, the manager, in order to remain competitive in the market, cannot accept to permanently limit production at the standard limit $L_{s}$ or ignore the possibility of an occasional emissions overflow. Hence, subcontracting can be an effective way for the company to avoid backlogs and reduce the negative effects in the environment at the same time. Indeed, items produced at the subcontractor manufactory generate less harmful emissions but with a higher production cost.

In the light of this discussion, we start from the HPP and develop a modified one which introduces the emission level in the production planning decision and takes advantage of subcontracting to reduce emission and costs. In this context, the decision maker should consider a specific emission level beyond which in-house production is reduced and subcontracting is started. We propose a new control policy which consists in setting a voluntary emission limit $L_{v}$ that controls the production and the subcontracting rates based on the emission level. When called, the subcontractor provides products at a rate $\mathrm{u}_{2}$ during his up time and until the end of the control period.

Equations (8) and (9) present the proposed control policy for a given emission control period i: 


$$
\left\{\begin{array}{c}
\text { if } e(t)<L v: \\
u_{1}(t)=\left\{\begin{array}{clc}
U_{\max } & \text { if } & x(t)<Z^{*} \text { and } \alpha(t)=1 \\
d & \text { if } & x(t)=Z * \text { and } \alpha(t)=1 \\
0 & \text { if } & x(t)>Z * \text { or } \alpha(t)=0
\end{array}\right. \\
u_{2}(t)=0
\end{array}\right.
$$

The proposed policy consists in monitoring the emission level $\mathrm{e}(\mathrm{t})$ over an emission control period i. When the emission level is below the level $\mathrm{Lv}$, the policy involves inhouse production according to the classical HPP without subcontracting (see equation 8).

When the emission level reaches $L_{v}$, the system can use subcontracted products to meet a proportion of the demand and reduce emissions (see equation 9) with respect to the hedging point policy. Both in-house production and subcontracting rates depend on the inventory level $(x(t))$ and the availability of both manufacturing systems $(\alpha(t), \beta(t))$.

$$
\left\{\begin{array}{c}
u_{1}(t)=\left\{\begin{array}{cl}
\text { if } e(t) \geq L v: \\
U_{\max } & \text { if } x(t)<Z^{*} \text { and } \alpha(t)=1 \text { and } \beta(t)=0 \\
\operatorname{Max}\left(\left(U_{\max }-u_{2}{ }^{*}\right), 0\right) & \text { if } x(t)<Z^{*} \text { and } \alpha(t)=1 \text { and } \beta(t)=1 \\
d & \text { if } x(t)=Z^{*} \text { and } \alpha(t)=1 \text { and } \beta(t)=0 \\
\operatorname{Max}\left(\left(d-u_{2}{ }^{*}\right), 0\right) & \text { if } x(t)=Z^{*} \text { and } \alpha(t)=1 \text { and } \beta(t)=1 \\
0 & \text { if } x(t) \leq Z^{*} \text { and } \alpha(t)=0 \text { and } \forall \beta(t) \\
0 & \text { if } x(t)>Z^{*}
\end{array}\right. \\
u_{2}(t)=\left\{\begin{array}{lll}
u_{2}^{*} & \text { if } \quad x(t) \leq Z^{*} \text { and } \beta(t)=1 \text { and } \forall \alpha(t) \\
0 & \text { if } & x(t) \leq Z^{*} \text { and } \beta(t)=0 \text { and } \forall \alpha(t) \\
& 0 & \text { if } x>Z^{*}
\end{array}\right.
\end{array}\right.
$$

This policy is a voluntary commitment which consists in setting a specific limit that controls the production and subcontracting rates, based on the inventory and emission levels. 


\section{Resolution approach}

An approach combining simulation and statistical optimization methods is used, as in Ben-Salem et al. (2015a) and Assid et al. (2014), in order to solve the problem. This approach is described in the following main steps as presented in Figure 2. The definition of the control policy is the first step; the structure was established in Section 3 and presented by equations (8) and (9). This policy is used to control inventory-production and emission levels based on different control parameters (factors) $Z, u_{2}$ and $L_{v}$. In the next step, a continuous-discrete simulation model is built to describe the system dynamics using the control policy as an input and the total cost as an output (see section 5). Then, an experimental design approach defines the experimental domain to conduct several experiments and thus evaluate the system performance. The effects of the factors and their interactions (ANOVA) on the response variable (total cost) through a minimal set of simulation experiments. Later, the response surface methodology is used to establish the relationship between the significant main factors, their interactions and the output variable (total cost). Thus, the optimal values of the control factors $\left(\mathrm{Z}, \mathrm{u}_{2}, \mathrm{~L}_{\mathrm{v}}\right)$ which minimize the total cost incurred are determined. At the end, sensitivity analyses are performed to evaluate the proposed control policy and the robustness of the resolution approach.

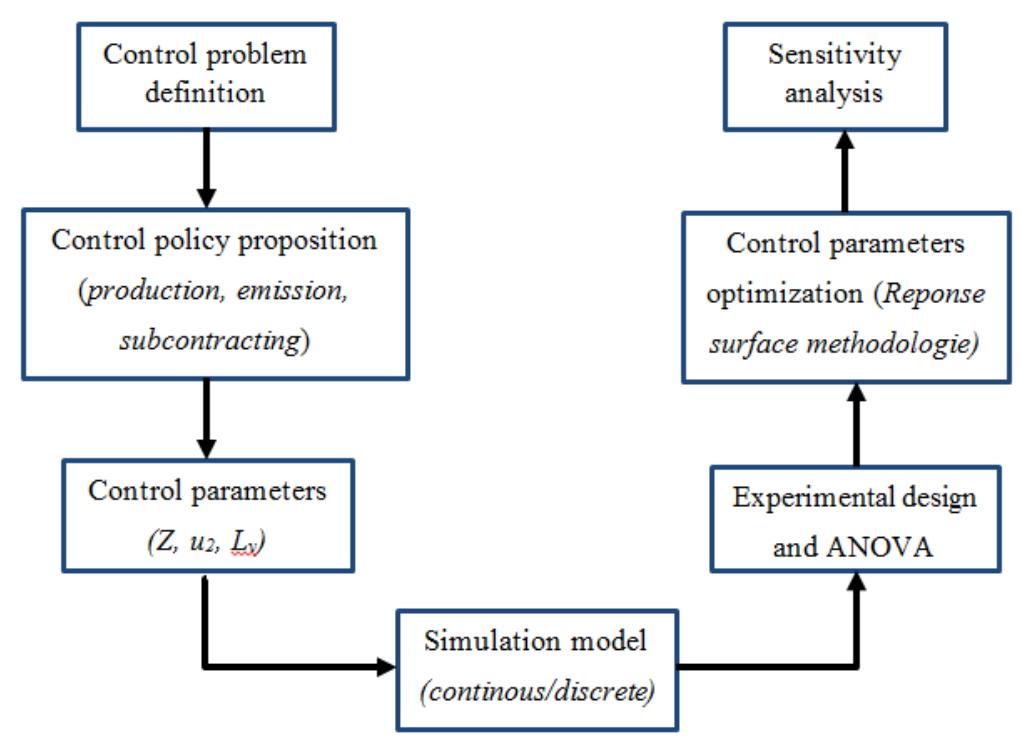

Figure 2 : Proposed resolution approach 


\section{Simulation model}

In this paper, we use the "ARENA" simulator with $\mathrm{C}^{++}$routines to develop a combined discrete-continuous simulation model. This type of model has shown the advantage of using this combination in terms of simulation time and reproducibility of the system dynamics (Assid et al. 2014). Figure 3 presents the diagram of the simulation model.

The model is initialized by defining the parameters required for the simulation $(d, M T T R$, simulation run time, etc.) (block 1). The manufacturing system (block 2) then allows the production of parts according to the production policy (block 3) presented by equations (8) to meet the demand rate (block 4). The machine is subject to random failures and repair activities (block 5). The state equations (block 6) describe the variation of inventory level $x(t)$ and the emission level $e(t)$. The simulation time advances (block 7) and the model updates the inventory and the emission levels (block 8). The emission level is controlled (block 9) in order to check the condition $e(t) \geq L_{v}$. When e(t) reaches the level of $\mathrm{L}_{\mathrm{v}}$, the production policy changes according to equation (9) (block 10); inhouse production is then reduced and subcontracting begun (block 11). Note that the subcontractor system is also subject to random stoppage and maintenance activities (block 12). Finally, we calculate the cost according to the following variables: inventory and backlog $\left(x^{+}\right.$and $\left.x\right)$, emission, production and subcontracting levels (block 13). 


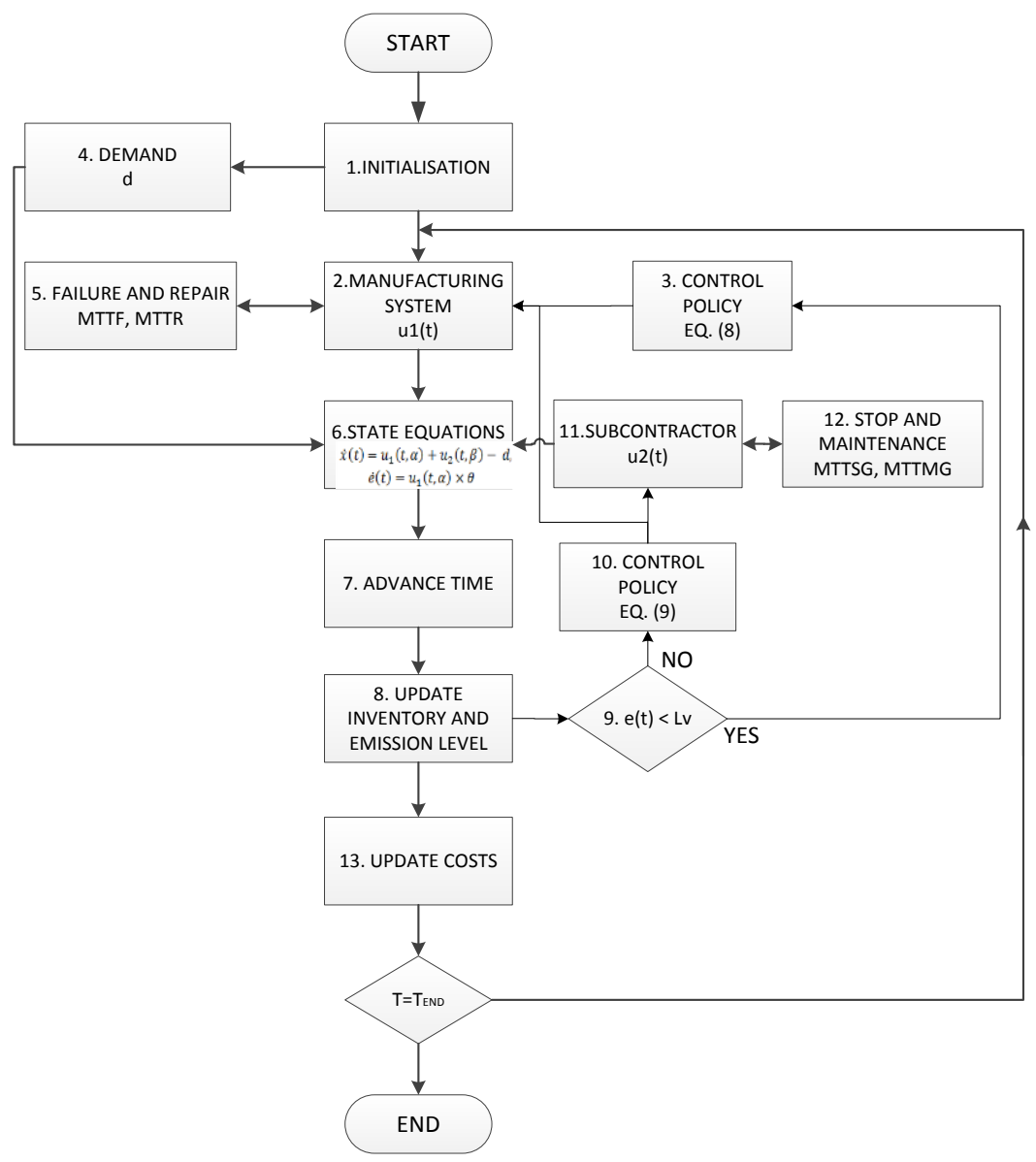

Figure 3: Diagram of the simulation model

In order to validate the simulation model, the variation of $x(t), e(t), u_{1}(t)$ and $u_{2}(t)$ over time is generated by the simulator. Figure 4 presents the results obtained when the system parameters are set to $U_{\max }=3, d=2, u_{2}=1, Z=10, L_{v}=150, L_{s}=100$ and $T_{i}=100$ units of time (UT), respectively: 


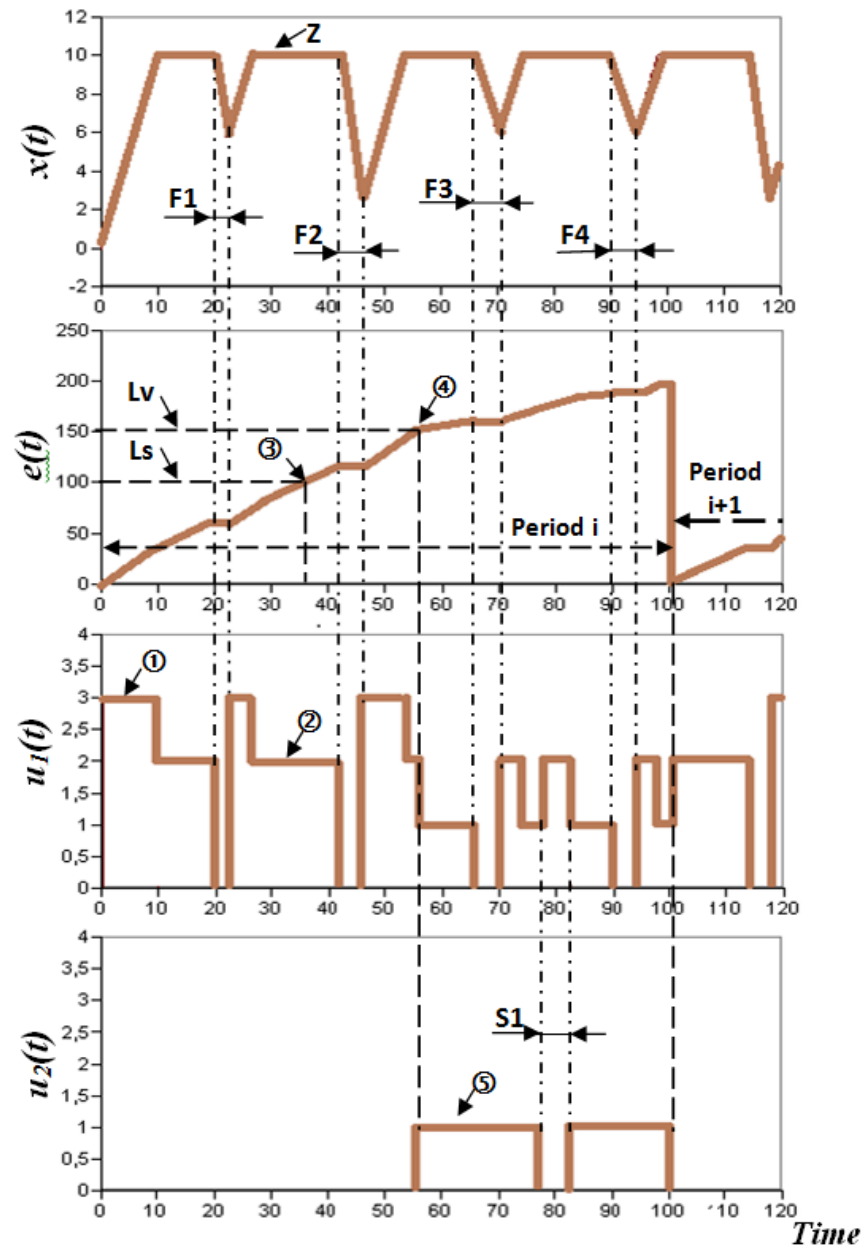

Figure 4: $\quad$ Variation of $x(t), e(t), u_{1}(t)$ and $u_{2}(t)$ over time

From Figure 4, when:

- $0 \leq \mathrm{t}<56 \mathrm{UT}$, the manufacturing system produces according to the classical HPP, with $Z=10$; the production rate $u_{1}(t)=U_{\max }=3$ if $x(t) \leq Z($ see 1 in Figure 4$)$ and $u_{1}(t)=d=2$ if $x(t)=Z$ ( see 2 in Figure 4). The emission level increases as a function of the production rhythm. When a random failure (such as F1 or F2) occurs, the production is stopped, and therefore, the cumulative emission level remains at the same value. Production is restarted after a random repair activity. The simulation time advances and the emission level reaches the standard limit $L_{s}$ at $\mathrm{t}=36 \mathrm{UT}$ (see 3 in Figure 4). From this point, an emission cost is added to the other costs (inventory, backlog and production). 
- $56 \leq \mathrm{t}<78 \mathrm{UT}$, the emission level $e(t)$ reaches the voluntary limit $L_{v}$ at $\mathrm{t}=56 \mathrm{UT}$ (see 4 in Figure 4), and hence, the production rate is reduced and subcontracting is started (see 5 in Figure 4 ); $u_{1}(t)+u_{2}(t)=2+1=U_{\max }$ if $x(t) \leq Z$ and $u_{1}(t)+u_{2}(t)=1$ $+1=d$ if $x(t)=Z$. Therefore, the emission rate decreases, which explains the change of the slope in the emission level graph. At $\mathrm{t}=65 \mathrm{UT}$, a new failure (F3) occurs.

- $78 \leq \mathrm{t}<90 \mathrm{UT}$, at $\mathrm{t}=78$, shutdown of the subcontractor production system (S1) occurs, as presented in the subcontracting rate graph $\left(u_{2}(t)=0\right)$ ), and the demand is satisfied from in-house production $\left(u_{l}(t)=2=d\right)$ alone. Then, at $\mathrm{t}=82 \mathrm{UT}$, the subcontracting is restarted $\left(u_{1}(t)+u_{2}(t)=1+1=d\right)$ after the subcontractor maintenance activity is completed.

- After $90 \leq \mathrm{t}<100 \mathrm{UT}$, the simulation time advances and another failure (F4) occurs at $\mathrm{t}=90 \mathrm{UT}$, before the end of the control period $\mathrm{i}$ at $\mathrm{t}=100 \mathrm{UT}$. From this moment, the cumulative emission level is reset to zero and subcontracting is stopped for the beginning of the next control period.

Based on several verifications and validation simulation runs, we can affirm that our simulation model adequately describes the dynamic of the system under study.

\section{Numerical example}

In this section, we use the resolution approach adopted in order to find the optimal total cost and optimal values of the parameters $\left(Z, u_{2}, L_{v}\right)$ defining the control policy. Therefore, an illustrative numerical example is defined, followed by a sensitivity analysis.

Table 1 summarizes the different parameters of the operations and costs characterizing the system for a basic case.

Table 1: Parameter values for the basic case

\begin{tabular}{|c|c|c|c|c|c|c|c|c|}
\hline Parameter & d & $\mathbf{U}_{\max }$ & MTTF & MTTR & $\mathbf{L}$ & $\mathrm{C}^{+}$ & $\mathbf{C}^{-}$ & \\
\hline Value & 100 & 125 & $\operatorname{Exp}(8 \mathrm{UT})$ & Exp (0.5UT) & 550000 & 1 & 20 & \\
\hline Parameter & $\mathbf{C}^{\mathrm{e}}$ & $\mathbf{C}_{\mathrm{s}}$ & $\mathbf{C}_{p}$ & $\mathbf{a}$ & b & MTSG & MTMG & $\mathbf{T}_{\mathbf{i}}$ \\
\hline Value & 3 & 6 & 3 & 0.5 & 2 & Exp (1UT) & Exp (20UT) & $5760 \mathrm{UT}$ \\
\hline
\end{tabular}


We adopt a full factorial design $3^{3}$ with five replications for each combination of the factors $\left(Z, u_{2}, L_{v}\right)$, which means we have 135 simulation experiments. The levels of each factor are presented in Table 2. The duration of each simulation is set to 500,000 UT to ensure that the steady-state is reached.

Table 2: Factor levels

\begin{tabular}{|c|c|c|c|}
\hline Factor & Low & Medium & High \\
\hline $\boldsymbol{L}_{\boldsymbol{v}}$ & 530,000 & 565,000 & 600,000 \\
\hline $\boldsymbol{Z}$ & 50 & 90 & 130 \\
\hline $\boldsymbol{u}_{2}$ & 0 & 62.5 & 125 \\
\hline
\end{tabular}

\subsection{RSM model and optimization}

The statistical processing of the data is carried out using the "STATGRAPHICS" software, which is used to perform the ANOVA. Thus, we obtain the effects of independent variables (policy parameters), their interactions, and their quadratic effects on the dependent variable (total cost).

For the selected system parameters (Table 1), the correlation coefficients $\mathrm{R}_{\text {adjusted }}^{2}$ found is equal to $95.35 \%$, which is sufficiently high to judge the good quality of the model. In the same vein, an analysis of the residual normality and of the homogeneity of variance was also carried out to check the conformity of the model.

The second order RSM model for the proposed control policy is given by:

$$
\begin{aligned}
& \widehat{\operatorname{Cost}}=641.758+1.2720110^{-4} \times \mathrm{L}_{v}-2.71879 \times \mathrm{Z}+0.866834 \times \mathrm{u}_{2}- \\
& 3.0037510^{-6} \times \mathrm{L}_{v} \times \mathrm{u}_{2}+1.1814510^{-2} \times \mathrm{Z}^{2}-1.365910^{-3} \times \mathrm{Z} \times \mathrm{u}_{2}+ \\
& 9.8196210^{-3} \times \mathrm{u}_{2}^{2}
\end{aligned}
$$

Figure 5.a and 5.b present the Pareto diagram and the estimated response surface of the model, respectively. 


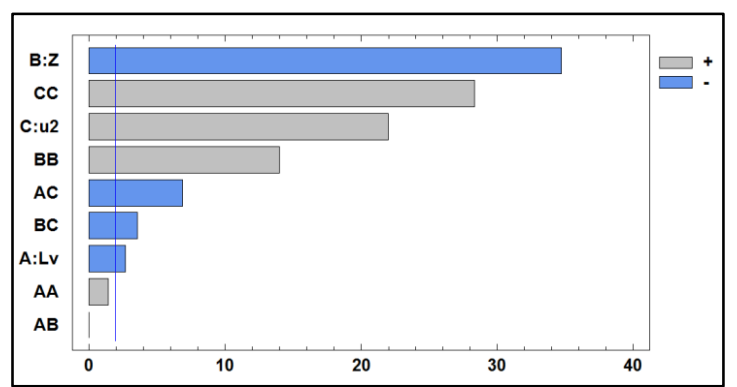

(a). Pareto Diagram

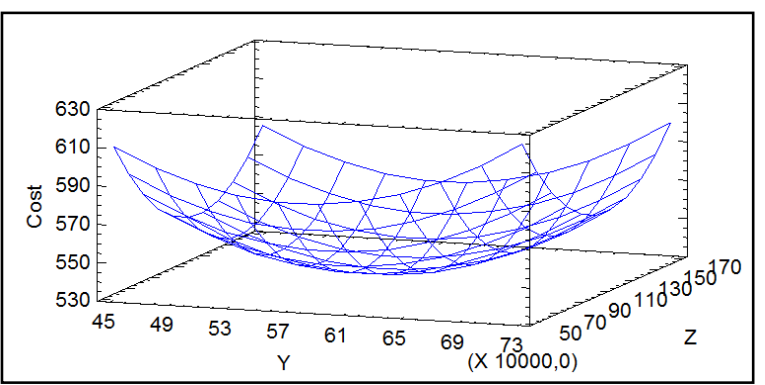

(b). Estimated response surface

Figure 5: Optimization results

The optimal policy to apply for this manufacturing system case study is defined by optimal parameters summarized in Table 3. For the sake of comparison, we also present, in the same table, the results of the optimization when the classic HPP is adopted for the manufacturing system. Note that the classical HPP does not take into account the emission level in the production decision, nor does it allow the system to resort to subcontracting $\left(u_{2}(t)=0, \forall e(t)\right)$. Therefore, we use a polynomial regression model in order to optimize its unique HPP parameter (Z), as in Kenné and Gharbi (2000). The model obtained is presented by the following equation:

$$
\widehat{\operatorname{Cost}}=725.973-2.8853 \times \mathrm{Z}+0.0122047 \times \mathrm{Z}^{2}
$$

Table 3: Optimization results

\begin{tabular}{|c|c|c|c|c|c|}
\hline $\begin{array}{c}\text { Control } \\
\text { Policy }\end{array}$ & Factor & Optimum & Cost* & $\boldsymbol{R}_{\text {adjusted }}^{2}$ & Confidence interval (95\%) \\
\hline \multirow{2}{*}{$\begin{array}{c}\text { Proposed } \\
\text { policy }\end{array}$} & $Z^{*}$ & 118 & & & \\
\cline { 2 - 3 } & $\boldsymbol{u}_{2}^{*}$ & 51.893 & 530.898 & $95.35 \%$ & {$[529.64 ; 532.07]$} \\
\cline { 2 - 6 } $\boldsymbol{L}_{v}^{*}$ & 574,235 & & & \\
\hline $\begin{array}{c}\text { Classical } \\
\text { HPP }\end{array}$ & $Z^{*}$ & 118 & 555.44 & $97.29 \%$ & {$[554.05 ; 558.82]$} \\
\hline
\end{tabular}

To cross-check the validity of our models, we confirm that the optimal cost for each control policy falls within the confidence interval at a 95\% confidence level (see Table 3 ). This confidence interval is obtained using $n=25$ replications of the simulation models. 
From Table 3, for the selected system parameters (Table 1), we note that the proposed control policy presents an economic advantage, compared to the classical HPP, with a $4.42 \%$ reduction in total costs. On the other hand, the results show that the proposed policy reduces the average quantity of emissions to $640.407 \times 10^{3}$ emission unit/control period, compared to $713.360 \times 10^{3}$ emission unit/control period for the classical HPP, a reduction of $10.23 \%$ in terms of emissions generated from the in-house production. These improvements are mainly due to the ability of the proposed policy to better control the production rate and the efficient use of subcontractor with clean technology, such as to obtain a good compromise between economic (cost) and environmental aspects (emission).

\subsection{Sensitivity analysis}

In this section, a sensitivity analysis is conducted to illustrate the effect of the variation of the cost parameters on the proposed control policy. This analysis provides further evidence of the usefulness and robustness of our resolution approach. Table 4 shows the results of the sensitivity analysis. From this table, we note that the economic gain of the proposed control policy compared to the classical HPP can reach 5.55\%.

Table 4: Results of sensitivity analysis

\begin{tabular}{|c|c|c|c|c|c|c|c|c|c|c|c|}
\hline \multirow{2}{*}{ Case } & \multicolumn{5}{|c|}{ Cost parameters } & \multicolumn{4}{|c|}{ Control policy parameters } & \multirow{2}{*}{$\begin{array}{c}\text { Gain/HPP } \\
(\%)\end{array}$} & \multirow{2}{*}{ Remark } \\
\hline & $C^{+}$ & $C$ & $C^{e}$ & $C_{p}$ & $C_{s}$ & $Z^{*}$ & $u_{2}^{*}$ & $L_{v} *$ & Cost* & & \\
\hline 1 & 1 & 20 & 3 & 3 & 6 & 118 & 51.893 & 574,235 & 530.898 & 4.42 & Basic case \\
\hline 2 & 0.8 & 20 & 3 & 3 & 6 & 126 & 52.57 & 574,754 & 509.545 & 4.63 & $\mathbf{Z}^{* \uparrow}, \mathbf{u}_{\mathbf{2}}{ }^{* \uparrow}, \mathbf{L}_{\mathbf{v}}{ }^{*} \uparrow$ \\
\hline 3 & 1.2 & 20 & 3 & 3 & 6 & 110 & 51.22 & 573,658 & 550.708 & 4.24 & $\mathbf{Z}^{*} \downarrow, \mathbf{u}_{\mathbf{2}}{ }^{*} \downarrow, \mathbf{L}_{\mathbf{v}}{ }^{*} \downarrow$ \\
\hline 4 & 1 & 15 & 3 & 3 & 6 & 105 & 51.61 & 571,537 & 517.567 & 3.7 & $\mathbf{Z}^{*} \downarrow, \mathbf{u}_{\mathbf{2}}{ }^{*} \downarrow, \mathbf{L}_{\mathbf{v}}{ }^{*} \downarrow$ \\
\hline 5 & 1 & 25 & 3 & 3 & 6 & 126 & 52.234 & 577,211 & 541.654 & 5.13 & $\mathbf{Z}^{*} \uparrow, \mathbf{u}_{\mathbf{2}} * \uparrow, \mathbf{L}_{\mathbf{v}} * \uparrow$ \\
\hline 6 & 1 & 20 & 2.5 & 3 & 6 & 118 & 48.138 & 584,589 & 522.611 & 3.37 & $\mathbf{Z}^{*} \leftrightarrow, \mathbf{u}_{\mathbf{2}}{ }^{*} \downarrow, \mathbf{L}_{\mathbf{v}}^{*} \uparrow$ \\
\hline 7 & 1 & 20 & 3.5 & 3 & 6 & 118 & 56.12 & 566,279 & 538.395 & 5.55 & $\mathbf{Z}^{*} \leftrightarrow, \mathbf{u}_{\mathbf{2}}{ }^{*} \uparrow, \mathbf{L}_{\mathbf{v}}{ }^{*} \downarrow$ \\
\hline 8 & 1 & 20 & 3 & 2 & 6 & 118 & 45.008 & 584,896 & 440.243 & 3.34 & $\mathbf{Z}^{*} \leftrightarrow, \mathbf{u}_{\mathbf{2}}{ }^{*} \downarrow, \mathbf{L}_{\mathbf{v}}{ }^{*} \uparrow$ \\
\hline 9 & 1 & 20 & 3 & 4 & 6 & 118 & 58.796 & 558,501 & 619.553 & 5.48 & $\mathbf{Z}^{*} \leftrightarrow, \mathbf{u}_{2}{ }^{*} \uparrow, \mathbf{L}_{\mathbf{v}}{ }^{*} \downarrow$ \\
\hline 10 & 1 & 20 & 3 & 3 & 5.5 & 118 & 55.488 & 566,545 & 525.228 & 5.44 & $\mathbf{Z}^{*} \leftrightarrow, \mathbf{u}_{\mathbf{2}}{ }^{*} \uparrow, \mathbf{L}_{\mathbf{v}}{ }^{*} \downarrow$ \\
\hline 11 & 1 & 20 & 3 & 3 & 6.5 & 118 & 48.329 & 580,561 & 536.016 & 3.5 & $\mathbf{Z}^{*} \leftrightarrow, \mathbf{u}_{2}{ }^{*} \downarrow, \mathbf{L}_{\mathbf{v}}^{*} \uparrow$ \\
\hline
\end{tabular}


- Variation of $\mathrm{C}^{+}$and $\mathrm{C}^{-}$: From Table 4, the variation of $\mathrm{C}^{+}$and $\mathrm{C}^{-}$has an opposite effect on the control policy parameters. Let us start with the critical threshold, when $\mathrm{C}^{+}$increases (case 3) (respectively $\mathrm{C}^{-}$decreases (case 4)), the critical threshold $Z$ decreases to avoid additional inventory cost. The opposite occurs when $\mathrm{C}^{+}$decreases (case 2) (respectively $\mathrm{C}^{-}$increases (case 5)).

On the other hand, the results show that the variation of the parameters $L_{v}$ and $u_{2}$ is related to the variation of the critical threshold $\mathrm{Z}$. Indeed, we notice that when $\mathrm{Z}$ increases (case 2 and case 5), the system draws on its high stock to meet demand before starting subcontracting by increasing $\mathrm{L}_{\mathrm{v}}$.

Regarding $\mathrm{u}_{2}$, if the system increases the critical threshold due to the variation of the inventory or backlog cost $\left(\mathrm{C}^{+}\right.$decreases (case 2$)$ or $\mathrm{C}^{-}$increases (case 5)), the subcontracting rate increases. In fact, it is more advantageous to increase the stock from subcontracted products than from in-house production in order to avoid additional emission costs. When $Z^{*}$ decreases (cases 3 and 4), the opposite effects occur on $\mathrm{L}_{\mathrm{v}}$ and $\mathrm{u}_{2}$.

- Variation of $C^{e}$ : The results show that the variation of $C^{\mathrm{e}}$ has no effect on Z. This makes sense since the critical threshold $\mathrm{Z}$ is mostly sensitive to $\mathrm{C}^{+}$and $\mathrm{C}^{-}$. However, the variation of $\mathrm{C}^{\mathrm{e}}$ mainly affects the voluntary limit $\mathrm{L}_{\mathrm{v}}$ and the subcontracting rate $\mathrm{u}_{2}$. Indeed, when $\mathrm{C}^{\mathrm{e}}$ increases (case 7 ), the emission cost increases, resulting in a decrease of $\mathrm{L}_{\mathrm{v}}$, causing subcontracting to start earlier. In the same vein, the subcontracting rate $\mathrm{u}_{2}$ increases to avoid additional emission costs. When $\mathrm{C}^{\mathrm{e}}$ decreases (case 6), the opposite occurs.

- Variation of $\mathrm{C}_{\mathrm{p}}$ and $\mathrm{C}_{\underline{s}}$ : When varying $\mathrm{C}_{\mathrm{s}}$ or $\mathrm{C}_{\mathrm{p}}$, no effect is observed on $\mathrm{Z}$. However, the variation of $\mathrm{C}_{\mathrm{p}}$ or $\mathrm{C}_{\mathrm{s}}$ has an effect on the decision relative to the subcontracting process. In fact, faced with an increase in $\mathrm{C}_{\mathrm{p}}$ (case 9) (respectively decrease in $\mathrm{C}_{\mathrm{s}}$ (case 10)), the system recommends more subcontracted products by reducing $\mathrm{L}_{\mathrm{v}}$ and increasing $\mathrm{u}_{2}$ to avoid additional in-house production costs. The opposite occurs when $\mathrm{C}_{\mathrm{p}}$ decreases (case 8 ) (respectively $\mathrm{C}_{\mathrm{s}}$ increases (case 11)).

To conclude this sensitivity analysis, the results show that, for higher values of $C_{s}\left(C_{s}\right.$ $\geq 6.8$ ), when considering only the economic aspect, the system chooses to produce only in-house $\left(u_{2}(t)=0\right)$ to avoid subcontracted products. However, regarding the 
environmental issue, the subcontracting solution can be beneficial to reduce harmful emissions.

\subsection{Effect of subcontracting and production system availability}

As mentioned in the problem description, we defined the production system availability $D_{p}$ as the fraction of time during which the production system is available. In addition, to better approximate industrial reality, we assume, in this paper, that the subcontractor is unreliable. In this section, the effects of the subcontracting and the manufacturing system availability on the control policy parameters are analyzed. Table 5 summarizes the results obtained.

Table 5: Results of the variation of $D_{p}$ and $D_{s}$

\begin{tabular}{|c|c|c|c|c|c|c|c|}
\hline \multirow{2}{*}{ Case } & \multicolumn{2}{|c|}{ Availability } & \multicolumn{4}{|c|}{ Control policy parameters } & \multirow{2}{*}{ Remark } \\
\cline { 2 - 7 } & $\boldsymbol{D}_{\boldsymbol{s}}$ & $\boldsymbol{D}_{\boldsymbol{p}}$ & $\boldsymbol{Z}^{*}$ & $\boldsymbol{u}_{2}{ }^{*}$ & $\boldsymbol{L}_{v}{ }^{*}$ & Cost $^{*}$ & \\
\hline $\boldsymbol{I}$ & $\mathbf{9 5 . 2 3 \%}$ & $\mathbf{9 4 . 1 1 \%}$ & $\mathbf{1 1 8}$ & $\mathbf{5 1 . 8 9 3}$ & $\mathbf{5 7 4 , 2 3 5}$ & $\mathbf{5 3 0 . 8 9 8}$ & Basic case \\
\hline $\mathbf{2}$ & $95.23 \%$ & $96.15 \%$ & 69 & 40.272 & 594,559 & 480.297 & $\mathbf{Z}^{*} \downarrow, \mathbf{u}_{\mathbf{2}}{ }^{*} \downarrow, \mathbf{L}_{\mathbf{v}}{ }^{*} \uparrow$ \\
\hline $\mathbf{3}$ & $97.22 \%$ & $94.11 \%$ & 113 & 61.372 & 568,270 & 520.914 & $\mathbf{Z}^{*} \downarrow, \mathbf{u}_{2}{ }^{*} \uparrow, \mathbf{L}_{\mathbf{v}}{ }^{*} \downarrow$ \\
\hline
\end{tabular}

It is important to note that the results found are logical and confirm our expectations. Indeed, we note that greater priority is given to in-house production when the production system availability increases (case 2), which explains the increase of $\mathrm{L}_{\mathrm{v}}$ and the decrease of the subcontracting rate $\mathrm{u}_{2}$. On the other hand, the results show that when the subcontractor availability increases (case 3), in-house production is reduced to allow more subcontracting by reducing $\mathrm{L}_{\mathrm{v}}$ and increasing $\mathrm{u}_{2}$. In other words, the system sees greater benefit in using a subcontractor, which has greater availability. Moreover, for both the production system and the subcontractor, we note that increasing the availability leads to a decrease in the critical threshold $\mathrm{Z}$ because the backlog risk is reduced.

Another observation is that for a low subcontractor availability $\left(D_{s} \leq 90 \%\right)$, the system produces only in-house $\left(u_{2}(t)=0\right)$ because subcontracting does not provide any economic benefit. In fact, in this case, the optimal cost is equal to that obtained when the classical HPP is applied: Cost $^{*}=$ Cost $_{\mathrm{HPP}}^{*}=555.44$ (see Table 3$)$. 
To finish with this subsection, we conclude that the green subcontractor availability is a very significant indicator to be taken into account because it has a direct effect on the economic as well as the environmental issue of the company.

\section{Decision support: Choosing whether or not to subcontract}

From the previous sections, we see that subcontracting can be used to improve the company's environmental strategy and minimize its total costs. The key idea is to reduce in-house production $\left(u_{1}(t)\right)$ and take orders from a green subcontractor $\left(u_{2}(t)\right)$ when emission costs increase. However, the results show that the effectiveness of this solution (subcontracting) depends on the characteristics of the subcontractor (cost $\mathrm{C}_{\mathrm{s}}$ and availability $\mathrm{D}_{\mathrm{s}}$ ). Indeed, from Section 6.2, we conclude that compared to the classical HPP, subcontracting does not present any economic advantage when $C_{s} \geq 6.8$. In the same vein, availability is an important issue to take into account when deciding whether or not to subcontract, as explained in Section 6.3. In fact, for low subcontractor availability $\left(D_{s} \leq 90 \%\right)$, the manager meets demand solely through in-house products. For both cases (high $\mathrm{C}_{\mathrm{s}}$ and/or low $\mathrm{D}_{\mathrm{s}}$ ), the proposed control policy is equivalent to the classical HPP with $u_{2}(t)=0$ and $Z=Z_{H P P}=118$, leading to the same optimal cost value, 555.44 .

Hence, in this section, the experimental resolution approach used in this paper provides the advantage of allowing further analysis in order to address the aspects related to the subcontracting process. This study aims to propose a tool to support decisions allowing the manager to choose the green subcontractor based on its characteristics $\left(C_{s}\right.$ and $\left.D_{s}\right)$ and thereby achieve the economic objectives of the company. In extreme cases, the company can accept to produce only in-house when the subcontracting process has no economic benefit.

The approach consists in considering the subcontracting $\operatorname{cost} \mathrm{C}_{\mathrm{s}}$ as an independent variable to be optimized along with other independent variables $\left(\mathrm{Z}, \mathrm{u}_{2}, \mathrm{~L}_{\mathrm{v}}\right)$. Then, the total cost (dependent variable) is maintained at the value $\operatorname{Cost}_{\mathrm{HPP}}^{*}=555.44$ for different subcontractor availability cases. This allows obtaining the indifference curve presented in Figure 6. 


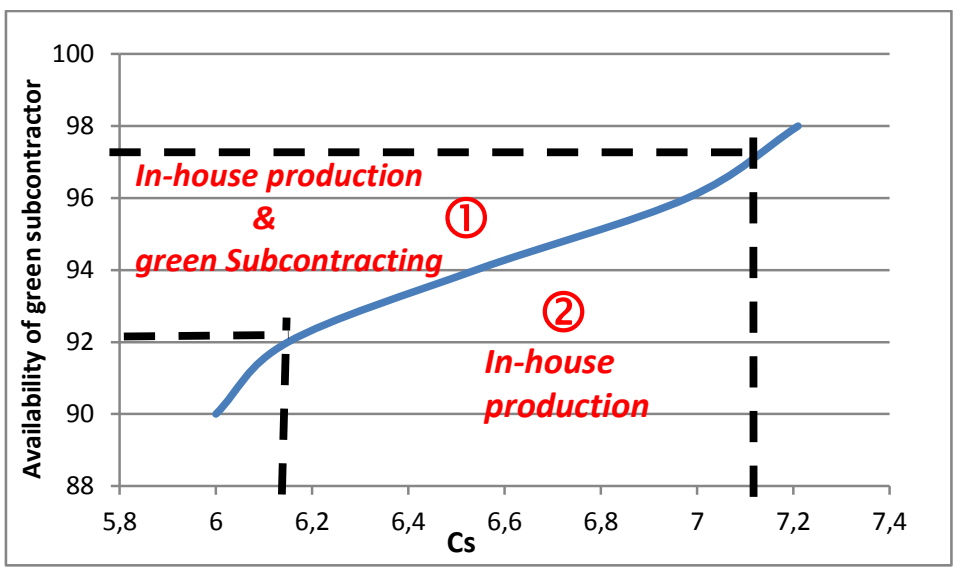

Figure 6: Indifference curve

Form Figure 6, we can distinguish two main zones: a first zone (see (1) in the Figure 6) where the system recommends subcontracting, in addition to in-house production, to reduce emissions generated as well as the total cost; in the second zone (see (2) in the Figure 6) in-house production is more profitable. The curve between the two zones indicates that subcontracting has no effect on the total cost.

A general observation that can be made is that when the green subcontractor provides high availability, the company agrees to pay a more expensive subcontracting cost. For example, for a subcontractor availability of only $D_{s}=92 \%$, the manager could pay up to $\mathrm{C}_{\mathrm{s}}=6.15$, otherwise he has no economic advantage in dealing with this subcontractor. However, the manager can accept to pay more, up to $\mathrm{C}_{\mathrm{s}}=7.1$, for a subcontractor that guarantees higher availability $\left(D_{s}=97 \%\right)$. We note that the previous results remained valid when the system parameters (MTTR, MTTF, $\mathrm{C}^{+}, \mathrm{C}^{-} \ldots$ ) vary. Indeed, the curve shape is preserved with different system parameters.

\section{Conclusion}

This paper addresses the integration environmental considerations into the manufacturing system control. Under the optimal control approach, we studied an unreliable manufacturing system that spews harmful emissions into the environment and may incur sanctions in the form of an environmental cost imposed by the relevant authorities. In addition, we assume that, due to various constraints, the company has not yet invested in green technologies. Thus, to improve its environmental strategy and reduce costs, items 
can be purchased, at a higher cost, from a subcontractor characterized by a high development on clean technology and a random availability.

The main contribution of this paper is that these aspects (production, subcontracting and emission) are considered simultaneously in a dynamic and stochastic context (failure, repair activities, availability) which, to the best of our knowledge, have never been considered as such in the literature. A control policy inspired from the HPP that integrates emission control in production and subcontracting decisions is developed. We used an experimental approach that combines simulation, experimental design and respond surface methodology in order to solve the problem and minimise the total cost, including inventory, backlog, production, emission and subcontracting costs. Through numerical examples, results show that the proposed control policy has an economic advantage as compared to the classical HPP, where subcontracting is not permitted. This economic gain reached $5.55 \%$, and can increases if $\mathrm{C}_{\mathrm{s}}$ decreases and/or $\mathrm{D}_{\mathrm{s}}$ increases. Furthermore, the proposed policy, which considers the subcontracting possibility, allows the company to considerably reduce its emissions. However, the economic advantages of such policy are strongly related to the subcontractor characteristics (availability, cost). For this reason, companies must take into account the green aspect in their future strategies and incorporate clean technology by taking advantage of government subsidies to be more ecologic and also more autonomous.

At the end of the paper, we presented a decision support system to help the manager choose whether or not to subcontract based on the subcontractor characteristics (availability/cost) thanks to the usefulness and advantage of our resolution approach.

Given that in the industrial domain, some companies have to use an environmental strategy based on trading emission permits, the consideration of this environmental policy in manufacturing system management can be an interesting subject for future research. 


\section{Ethical Statement}

This paper respects ethical standards:

- The manuscript has not been submitted to more than one journal for simultaneous consideration.

- The manuscript has not been published previously (partly or in full), unless the new work concerns an expansion of previous work (please provide transparency on the re-use of material to avoid the hint of text-recycling ("self-plagiarism")).

- A single study is not split up into several parts to increase the quantity of submissions and submitted to various journals or to one journal over time (e.g. "salami-publishing").

- No data have been fabricated or manipulated (including images) to support your conclusions

- No data, text, or theories by others are presented as if they were the author's own ("plagiarism"). Proper acknowledgements to other works must be given (this includes material that is closely copied (near verbatim), summarized and/or paraphrased), quotation marks are used for verbatim copying of material, and permissions are secured for material that is copyrighted.

- Consent to submit has been received explicitly from all co-authors, as well as from the responsible authorities - tacitly or explicitly - at the institute/organization where the work has been carried out, before the work is submitted.

- Authors whose names appear on the submission have contributed sufficiently to the scientific work and therefore share collective responsibility and accountability for the results.

- This paper does not pose any potential conflicts of interest

- Research in this paper do not involve Human Participants and/or Animals

\section{References}

Abernathy, F. H., Dunlop, J. T., Hammond, J. H., \& Weil, D. (2000). Control your inventory in a world of lean retailing. Harvard business review, 78(6), 169-176.

Assid, M., Gharbi, A., \& Hajji, A. (2014). Joint production and setup control policies of unreliable manufacturing systems minimizing the incurred total cost and taking into account other criteria. The International Journal of Advanced Manufacturing Technology, 72, 809-826.

Baas, L. (2007). To make zero emissions technologies and strategies become a reality, the lessons learned of cleaner production dissemination have to be known. Journal of cleaner production, 15(13), 1205-1216.

Ben-Salem, A., Gharbi, A., \& Hajji, A. (2015a). Environmental issue in an alternative production-maintenance control for unreliable manufacturing system subject to degradation. The International Journal of Advanced Manufacturing Technology, 77, $383-398$ 
Ben-Salem, A., Gharbi, A., \& Hajji, A. (2015b). An Environmental Hedging Point Policy to control production rate and emissions in unreliable manufacturing systems. International Journal of Production Research, 53(2), 435-450.

Bradley, J.R. (2004). A Brownian approximation of a production-inventory system with a manufacturer that subcontracts. Operations Research. 52(5), 765-784.

Brown, D. (2008). It is good to be green: environmentally friendly credentials are influencing business outsourcing decisions. Strategic Outsourcing: An International Journal, 1(1), 87-95.

Cebon, P. (1993). Corporate obstacles to pollution prevention. EPA J., 19, 20.

Chen, C. \& Monahan, G.E. (2010). Environmental safety stock: The impacts of regulatory and voluntary control policies on production planning, inventory control, and environmental performance. European Journal of Operational Research. 207, 1280-1292.

Chen, X., Benjaafar, S. \& Elomri, A. (2013).The carbon-constrained EOQ. Operations Research Letters. 41(2), 172-179.

Dahane, M., Dellagi, S., Clémentz, C. \& Rezg, N. (2011). Development of joint maintenance and production strategies in a subcontracting environment. International Journal of Production Research. 49(23), 6937-6961.

Drake, D., Kleindorfer, P.R. \& Van Wassenhove, L.N. (2012). Technology choice and capacity portfolios under emissions regulation. Harvard Business School Working Paper, Harvard University.

Hajej, Z., Dellagi, S., \& Rezg, N. (2014). Joint optimisation of maintenance and production policies with subcontracting and product returns. Journal of Intelligent Manufacturing, 25(3), 589-602.

Hajji, A., Gharbi, A. \& Kenne, J.-P. (2009). Joint replenishment and manufacturing activities control in a two-stage unreliable supply chain. International Journal of Production Research. 47(12), 3231-3251.

Kenne, J.-P. \& Gharbi, A. (2000). Production planning problem in manufacturing systems with general failure and repair time distributions. Production Planning \& Control. 11(6), 581-588. 
Kouedeu, A. F., Kenné, J. P., Dejax, P., Songmene, V., \& Polotski, V. (2014). Production and maintenance planning for a failure-prone deteriorating manufacturing system: a hierarchical control approach. The International Journal of Advanced Manufacturing Technology, 1-13.

Kumar, R. S., \& Subrahmanya, M. B. (2010). Influence of subcontracting on innovation and economic performance of SMEs in Indian automobile industry. Technovation, 30(11), 558-569.

Lambert, D. M., Emmelhainz, M. A., \& Gardner, J. T. (1996). Developing and implementing supply chain partnerships. The international Journal of Logistics management, 7(2), 1-18.

Li, S. (2014). Optimal control of production-maintenance system with deteriorating items emission tax and pollution R\&D investment. International Journal of Production Research. 52 (6), 1787-1807.

Ramudhin, A., Chaabane, A., Kharoune, M., \& Paquet, M. (2008). Carbon market sensitive green supply chain network design. In: Industrial Engineering and Engineering Management, 2008. IEEM 2008. IEEE International Conference, 10931097. IEEE.

Rivera-Gomez, H., Gharbi, A., \& Kenné, J. P. (2013). Joint control of production, overhaul, and preventive maintenance for a production system subject to quality and reliability deteriorations. The International Journal of Advanced Manufacturing Technology, 69(9-12), 2111-2130.

Sivakumar, R., Kannan, D., \& Murugesan, P. (2014). Green vendor evaluation and selection using AHP and Taguchi loss functions in production outsourcing in mining industry. Resources Policy.

Tan, B. (2004). Subcontracting with availability guarantees: production control and capacity decisions. IIE Transactions. 36 (8), 711-724.

Yang, J., Qi, X., \& Xia, Y. (2005). A production-inventory system with Markovian capacity and outsourcing option. Operations Research. 53 (2), 328-349. 